\title{
Phrases and the Expressions of Phrasing in Piano Performance
}

\author{
Siyin Li \\ The Music School of Dalian University, Dalian, China \\ Email: Siyinlisierra@foxmail.com
}

How to cite this paper: Li, S. Y. (2017). Phrases and the Expressions of Phrasing in Piano Performance. Creative Education, 8 , 2177-2186.

https://doi.org/10.4236/ce.2017.813148

Received: July 28, 2017

Accepted: October 28, 2017

Published: October 31, 2017

Copyright $\odot 2017$ by authors and Scientific Research Publishing Inc. This work is licensed under the Creative Commons Attribution International License (CC BY 4.0).

http://creativecommons.org/licenses/by/4.0/

\begin{abstract}
The article explains what phrasing is, and it analyses phrase and its basic components from the structure of syntax. It also discusses the factors and their relationships that effect. Having rationally analyzed and sensibly comprehended the form melody, mood, harmony and cadence and the following structure of syntax, it then introduces the skills which are always ignored. Music is an opposite article subject. This article only discusses the common phrasing during the romantic times and the time before it. The author uses many words such as "common" to express the relativity in piano performance. Special condition should apply special method. Phrasing expresses the extent of performer in comprehending the opuses. It can help performer reappearance opuses more closing.
\end{abstract}

\section{Keywords}

Phrasing, Motive, Section, Melody, Harmony, Cadence

\section{Introduction}

How to phrase is a very important subject in performers' studying and performing careers. It is art, which requires performers to have prime knowledge, skill, feeling and estimation. If you want to represent opuses exactly and integrally, you should know the logistic relations of phrases and the expressions of phrasing. Phrasing is not only disorderly and unsystematic, but also has some rules. By learning phrasing, you can make music rich and color with different motive signs.

Most domestic and overseas literatures explain phrasing with actual opuses and performing according as history or style of composer. In this article, the author makes phrase as a basic unit, discusses the rules in phrase's interior and re- 
lationship between phrases. Using these rules can help the performers making more exact annotations.

The factors affect the division of phrases and the relationship between the various factors. The division of musical works is influenced by many factors, even in the same work, different players dividing the phrases are also different. Why would this happen? This will need us to discuss the factors that affect the division of phrases, such as the period of the work, the style, the melody, the rhythm, the language tone, the harmony structure and so on. This article focuses on the interrelationships between phrases and melodies, phrases and rhythms, phrases and language, phrases and harmony structures. This is the theoretical basis and principles for performers to follow.

This article describes phrase from the syntactic structure analyzing the phrase and its composition. Article focuses on the factors that affect the division of the works and their relationships, based on the structure of the phrase as the basic theoretical basis, from the melody, tone, harmony and rhythm of the four aspects of the division of the rational analysis.

\section{Melody and Phrase}

Music is the expression of emotional language art. The expressive power of musical art has the same characteristics as human emotional thinking. Melody is the basic semantic symbol of music language, carrying the content of music art emotional expression. It is the basic elements of the combination of music unity. It is also the music image of the concentrated embodiment. Among the elements that make up the musical language, the melody is an integral part of the core. Melody is a part of the sound of music. It is the basis of music (Alder, 1999: 30-32). From the elements of the melody, it contains the basic elements of the composition of music thought including pitch relationship (tone relationship and melody line), rhythm, beat, sound and expression method. It even implied harmony thinking. From the nature of the melody, it is the vivid unity of the different elements of the musical language, so that all aspects of their own are subject to their artistic expression. Music content, style, genre, ethnic characteristics, generally first through the melody show, such as Bach's minuet, Chopin's Mazuka dance. Melody is the common form of music, no matter what form of the cultures and times (Gu, 1998: 22-26, 29-33, 46-70). And it is the most useful factor of artistic quality, just like the touchstone. A composer cannot be a composer if he does not have the ability to write melodies. Melody is the basis of music and soul.

The melody is based on the needs of the human mind's emotional movement, which is based on the tone and the beat, and it is constantly changing (Matsushi, 1983: 29-33, 45). It is born and developed with the development of the human thinking and language. When the composer expresses emotions through the melody, the tone being used first determines the nature of the emotion from the music. At the same time, it determines our style of melody in the cutting and re- 
organization of the melody, and also dedicates to highlight and emphasize the personality. Accompanied by the beat used, from the music that dominate the emotional movement of the basic rhythm, may be stretched and stretched constantly, it also may be clear and dynamic.

The two elements of the melody are pitch lines and rhythms. The pitch and rhythm are the same important for the composition of the melody. A melody is hard or impossible to become a melody if there is no rhythm (Tourek, 2003: 5). By using phrases and different rhythmic form of movement, you can express the light or heavy, soothing or eager, smooth or resistance, flexible or tough melody. The line-like movement of the crosstalk or the interval shows the appearance of the emotional movement in the voice tone. Through various arcs accompany the composer's re-creation, the music immediately reflects its own emotions and logic.

In the enjoyment of the rich content of the melody, the exact determination of its expression and development of the logic is the purpose of phrase. Describing the idea of melody is the primary responsibility of the phrase. The study of the basic expression of the phrases must be combined with the development of the melody line from the beginning (Melgie, 1985: 12-15). The movement of the melody is done by relying on the different issues of the sentence.

The analysis of the structure of the melody usually requires that the melody be divided into parts and units with content. The phrases are the first step in the performance of the melody (Eddock, 1978: 12-16). Do not damage the melody lines and its integrity, while not destroying the style of the work is the rules of phrase.

The phrase helps to highlight the climax of the melody. During the phrase, it is necessary to clearly understand the logical process of the melody line, that is, the starting point of each pattern, the basic melody line, the strength of the sense, the melody of the tone, the climax of the location and its corresponding Ups and downs, harmony and its function. Phrase according to the basic knowledge so that we can show the melody expression more accurately (But, 2004: 50 ). Because of the wide variety of musical works, the form of phrases is also diverse. In a work, there are maybe several climaxes, but the climax of the whole song must be considered firstly, the rest climaxes are only local climaxes. All kinds of climax are necessary for the development of the work. The upward melody is often accompanied by the strengthening of strength, while the downward movement of the melody was accompanied by a weakening of the intensity. The undulating form of the melody makes up and down jumps and turns, which can also make the hearing strong and weak, thus making it easier to judge the position of the climax of the works (Hamilton, 2002: 34).

Connection is a sign of phrasing, it just like the comma in language sentence; connection can be regarded as the theme or melody of the intermittent pause, mark (Weijieer, 1986: 22). It divides the continuous sound that makes the grada- 
tion much more clearer, playing an important role in the melody. Connection expression is to determine the meaning of the movement of the melody level distribution.

The most obvious connection is between the major chapters of music work, but the performance between the connection is not so obvious. It is necessary that the performer must have been trained in the basic skills of music, and thus has two important qualities: one is the potential music structure design ability to be good at determine the phrases correctly. The second is the ability of judging the meaning of each connection expression. The two above abilities will provide a good music melody.

There are efforts to control the expression of logic, and priority changes are important to correctly handle the melody of syntax (Levine, 2004: 41). The free handling of musical expressions is also extremely important for phrase methods. Rational use of free processing based on the sense of proportion and balance. The sense of proportion can help the player to avoid excessive increase in freedom, the sense of balance can increase coordination. If you do not consider the changes of music style and plot, it will make the performance lack proper uniformity. A syntactic phase that requires the performer do not increase or decrease the volume immediately but should increase or decrease it at the end of the sound intensity change (Tosh, 1984: 25-30). The mistake that often be made by beginners is failed to step by step in the grasping each sound strength, cannot adjust the volume on time. In the performance processing, when you deal with the gradually faster and gradually slow, you should not change from the beginning of the phrase, but should change in the follow-up part of the gradual. Of course, there is the opposite situation, the player in the melody expression requirements, must suddenly change the sound intensity, and should not use the progressive principle.

The above describes the relationship between melody, melody and phrases, and the use of these theories in piano playing can help the player to reproduce the melody structure of the musical piece more accurately.

\section{Language Tone and Phrase}

Language is a human-specific means of transport, people use language to convey ideas, exchange feelings (Shao, 1975: 72). The language is rich in emotional color and rich in sound color. Rich psychological feelings can be expressed through the physiological pronunciation of the tone. When people communicate in language and transmit ideas and attitudes, they often pour their subtle thoughts and emotions into the tone of the language and show themselves in the tone of the language.

The division of language and is like phrases in music. In the process of expressing thoughts and feelings, the voice, tone and so on of language are the means of expression. The statement and expression of music language, is the phrase as the basic unit to reflect the requirements of the performer (Zhao, 2000: 
163). The musical mood is the different division made by performers. It reflects their understanding level of music and artistic attainments. The tone is the contrast between the intensity of the phrase or the motive, and the contrast of the time extension is the recitation and expression of the music. It is one of the important means of expression of music sound image.

The musical language has its own prominent syllables. Let's consider the tone from the contrast of strength, the composer wrote the tempo notation from the beginning, in addition to showing the order of rhythm, it also shows the characteristics of the tone.

The tone is based on correct phrases. The ability to express or sing in an expression depends on its overall sense of the phase. The phrase is meaningful; it depends on the relationship between strong words and weak words. These two factors are fully represented in the sentence. The musical phase is logically the same as the statement of the language; they all have their own specific grammar law.

The phrases in music are similar to those of literary interrupted sentences. The wrong phrase is like wrong reading in the literary sentence. Reading different languages with different tones will have different meanings, and tone often expresses the meaning of questions or questions and answers.

The same phrase, using a different phrase division method, will produce a completely different performance. As in Example 1, different phrases result in the transfer of the focus of the phrase and the expression of the music are changed.
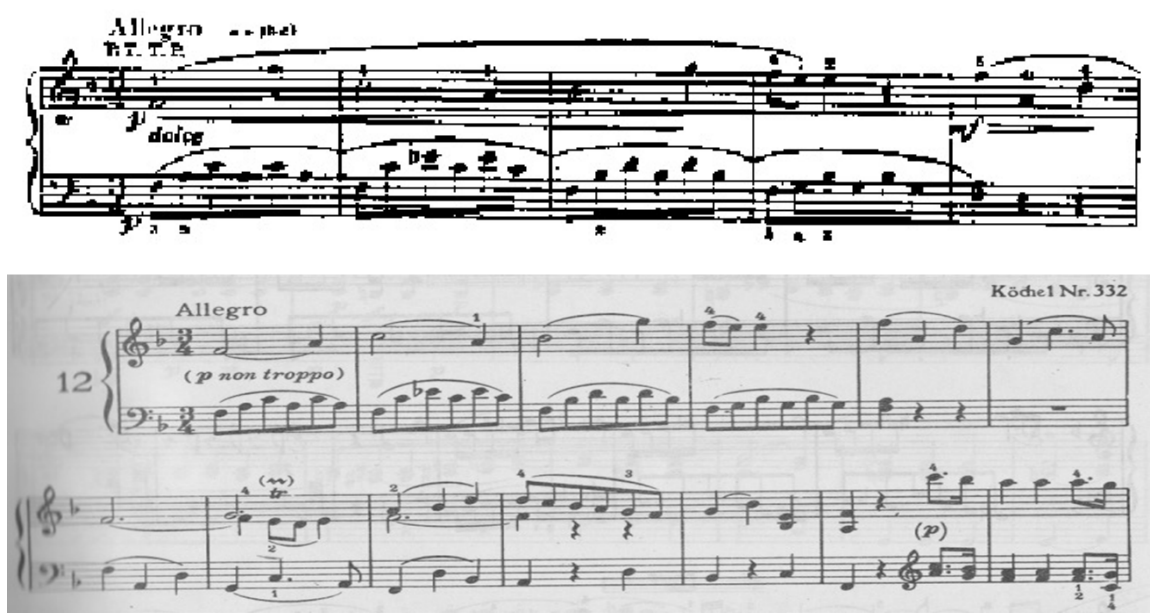

The above is Mozart K. 332/i of the beginning of the Epstein Hamilton version and Hans-Martin prepared Henry-Haier Terry check revision. Put aside the two versions of the good or bad do not say, just look at the two different phrase divisions of the same form of melody. A in the first eight notes of the 1 - 4 lines in a phrase, while the spectrum also marked dolce, left five and sound type has been extended into a connection, which are said to give the audience a singing, soft, long melody fragment; $\mathrm{B}$ in the first eight notes, every of two 
notes divided into one motivation, no expression of the terms in the spectrum, the first two harmony figures are in one group, from the third harmony figure, each of them are separated, giving a dynamic, lively, cheerful music melody image.

During the performance, the neglect of the phrase is like a drama actor did not read out the lines cadence full of emotional with the tone up and down. If the player himself does not understand the music phrases, then his performance must be like reading their own manuscripts with no rhythm, dull, bring the audience will be only boring. Always realize the recitation of the music we play and bring it to the audience. The player should have sensitive feeling on phrases (Chen \& Situ, 2000: 70-72).

Music phrases and language phrases have a lot in common: both statements must be persuasive, which is determined by the phrase point, the breath, and sentence focus. In logic, both require fluency, meaning clear, rigorous structure, and phrases appropriate. Different phrases will form a different tone, with a flexible artistry. We can compose the rhythm of the verse during reciting a poetry, music performance is also the same. The correct grasp of the phrases, can make us smooth playing.

The beauty of playing refers to the correct phrases. A successful music should be the artistic creation of rhythmic movements and tones of poetry. The language tone in music is the basic skill that we should pay great attention to in the process of playing and teaching. Musicians attach great importance to the important role of language expressions in the formation of musical expressions. Language expression can play a good role in inspiring music emotion, and can express music emotion accurately under the guidance of language expression (Egrett, 2005: 50-51). We should cultivate students' sense of clear phrase boundaries, breathing sensitive, make them have their own ability to grasp the whole music. In order to make the music tone need to have a listening experience and association thinking ability. We cannot use just a few words to discourse the entire music tone phenomenon clearly. Mood depends not only on the player's own understanding, but also depends on some objective factors. Only through continuous inspection, practice, we will not misunderstand the composer's music.

\section{Rhythm and Phrases}

The note must be organized in rhythm to become a melody. The focus of the phrase is closely related to the tone of the rhythm that is to be emphasized. The rhythm of the melody is an important part of the correct phrase. The wrong phrases break the melody rhythm balance of the whole music. The phrase of the music language is determined by the special nature of the conscious and planned combination of language units into the rhythm and rhythm of the framework.

The correct way of phrases is based on the correct rhythm. The rhythm of different characters, such as various dances rhythm, Polish dance, Mazurka and 
other rhythmic stress, also plays a direct role on the division of the phrase. Only with the correct phrases to explain the work, analysis and research rhythm of the different framework, performer can complete and accurate performance of the composer's music (Grout, 2000: 12). In order to use correct phrase to explain the work and express the music of the composer accurately, player need to analyze and study the rhythm frame of different works and master their different rhythmic characteristics.

During piano playing, in addition to the correct grasp of the rhythm, player also need to correctly phrases. If the phrases are compared as a pearl, then the overall sense of music is like a gold thread through the pearl. If you cannot handle the phrases well, it will not be carved fine details, which means no much value. Only to handle every phrase well, that we can receive a good sense of music, and converge into a whole with a higher art. Phrases are reasonable or not, is the key link of the overall music sense. Only through digging the music connotation seriously, phrasing by their own understanding, then the performance will be successful.

\section{Harmony Structure and Phrases}

In addition to the above three methods to understand and divide the breathing of melody and sentence reading, another sort of phrase is based on the analysis of its harmony structure. This mainly refers to the classical romantic music in which the main tone is the core (Shuter-Dyson, 1982: 55-56).

\subsection{Definition}

Harmony is the sound combination of two or more different sounds according to certain rules at the same time. It contains:

1) Chord, is the basic material of the harmony, consisting of three or more different sounds, according to the three-fold or other method, this is the longitudinal structure of the harmony.

2) Harmony Process, refers to the succession of the chords, this is horizontal movement of the harmony.

\subsection{Harmony's Role in Music}

With the gradual development of the main music, the role of harmony is becoming increasingly important. Its role in music is roughly 3aspects:

1) Vocal combination action. On the basis of the one-sided harmony group, each voice part intercompetitive synthesis cooperative adjustment.

2) Psychological constriction. Commuter Voice Advance, Convergence Formula, Tone-Promotion Bureau etc.

3) Content-oriented action. Voice color, texture containing compound formulation, other elements, model sound elephant, face present sound contents.

\subsection{The Performance of the Content}

Through the harmony color, texture and other factors, shaping the music image, 
performance music content. Harmony processing is an important writing skill of music creation, but also the basis of other techniques such as alignment, collocation, and music. Sometimes tunes are also derived from harmony.

Melody is an independent unit of performance of music, and it is relative to the harmony which is as background, throughout the phrase (Westerby., 1987: 45-46). Analysis the harmony process and the end type can get the concept of melody process and end clearly. The termination of the harmony process has the following three kinds: Authentic Cadence from V to I; Plagalcadence from IV to I; Compound authentic cadence.

These harmonies processes and cadences are the important signs of the end of the period. It prompts the beginning of the period, linked to each phrase regularly.

Different harmony function color, affecting the melody lines changing of tension and relaxation, the ups and downs.

The radical of the harmony is like the foundation of the building, and the melody is the shape and lines of the building. Sometimes a phrase is not only composed of single tone melody, but also by the harmony process directly. In this case, the highlight is not a single treble, but the various parts of harmony. See Example 2:

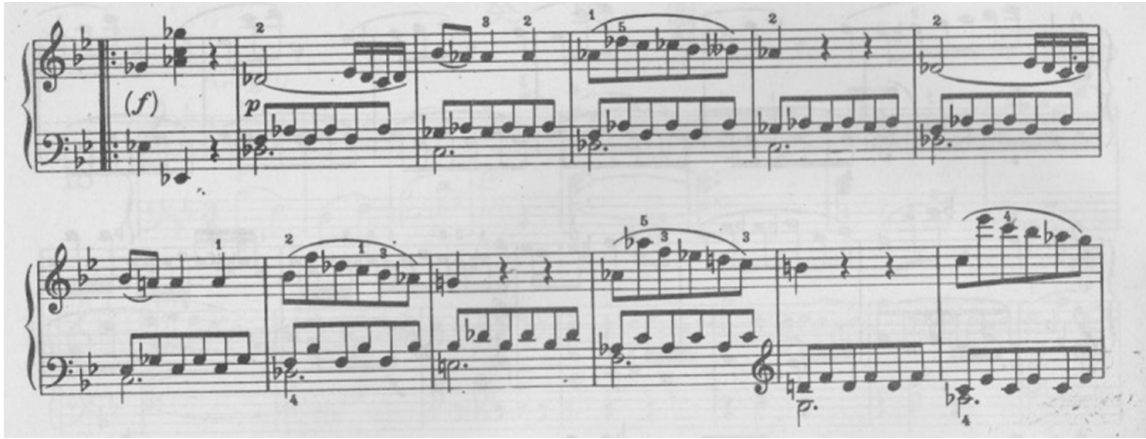

Analyze and play different harmony radical, listen to the harmony process, is very helpful for the understanding and grasping of the big melody. See Example 3 for the left hand of the root.

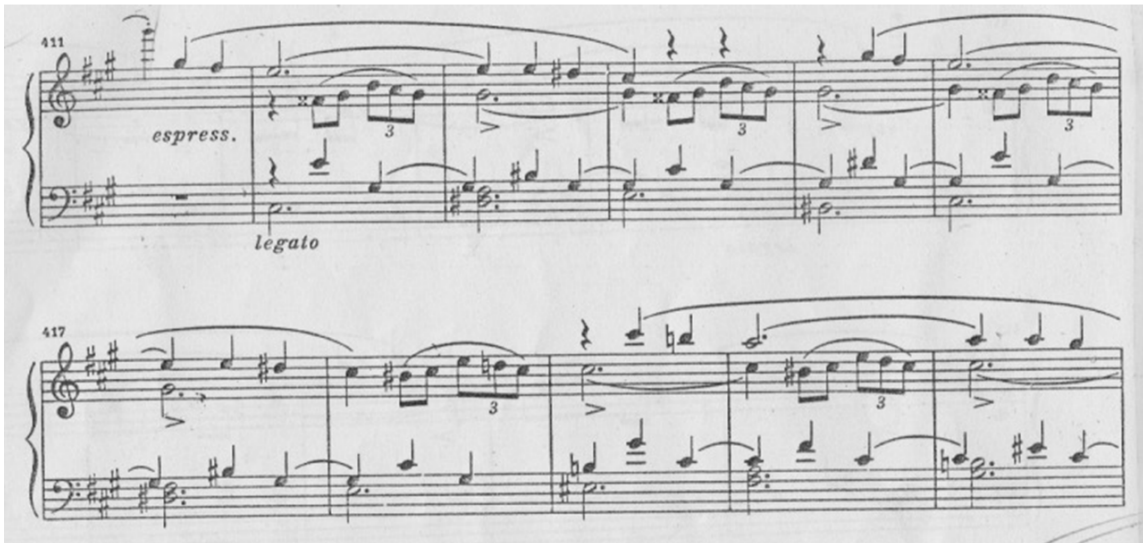




\section{Conclusion}

In the presentation of the process, music has never been carried out. According to the content of music and music needs, through different phrase adverb (like punctuation in the language), divided into different levels, different levels of syntactic structure units. Different people in the syntax structure will be different, resulting in different playing skills, playing different effects. Music is art, there is no absolute right and wrong boundaries. Each performer has his own unique understanding of the phrases. Understanding phrases and mastering phrases are very important to the performer. The purpose of this research on the method of phrase in piano playing is to make the player understand the music, logical reproduction music, and so on in the piano playing.

After analyzing and discussing, this paper introduces what is the phrase, analyzes the phrases and their composition from the syntactic structure, emphasizes the factors that influence the division of the phrases and the relationship between them, emphasizes the problem that the phrases are easy to be ignored, to deepen the relationship between the inner logic of the phrase, the overall handling of the expression of phrases. In order to accurately and completely show the music works, to be a successful pianist, mastering phrase is a necessary condition. Research phrases help fully understanding the content of music works, laying a foundation for the excellent music performance.

At last, because of the limitation of the author, this paper is only some basic research on the method of piano playing. These methods can only be used as the reference of the player, so the player's own analysis and judgment are needed. It should be noted that we cannot apply the analysis of cadence and phrase of classical romance harmony to the modern music melody. Modern music phrases are often asymmetric development of irregular phrases, the melody language is different from classical romance. This article only discusses the method of dealing with phrases in Romans and Romans before most cases, and does not have systematic analysis for other periods of phrases, which has certain limitations. The treatment of modern works needs to be further studied and discussed.

\section{References}

Alder, A. (1999). Concise Oxford Music History (pp. 30-32). Shanghai: Shanghai Music Publishing House.

But, C. Y. (2004). Children's Piano Teaching and Counseling (p. 50). Beijing: People's Music Publishing House.

Chen, Q. L., \& Situ, B. (2000). Piano Teaching Method (pp. 70-72). Chongqing: Southwest Normal University Press.

Eddock (1978). On Melody Art (pp. 12-16). Beijing: Central Conservatory of Music Press.

Egrett, H. J. (2005). Western Literature (pp. 50-51). Changsha: Hunan Literature and Art Publishing House.

Grout, D. J. (2000). A History of Western Music (p. 12). New York: W. W. Norton Company. 
Gu, C.Q. (1998). Music Syntactic Structure Analysis (pp. 22-26, 29-33, 46-70). Beijing: China Music Publishing House.

Hamilton, H.-P. (2002). Piano Playing in the Touch and Expression (p. 34). Beijing: People's Music Publishing House.

Levine (2004). The Basic Law of Piano Playing (p. 41). Beijing: People's Music Publishing House.

Matsushi (1983). On the Melody (pp. 29-33, 45). Beijing: People's Music Publishing House.

Melgie, J. M. (1985). Basic Music Teaching Method (pp. 12-15). Beijing: Full Music Press.

Shao, Y. Q. (1975). Pianist's Manual (p. 72). Beijing: Full Music Publishing,

Shuter-Dyson, R. (1982). The Psychology of Ability (pp. 55-56). London: Routledge Kegan \& Paul.

Tosh, E. (1984). Melody (pp. 25-30). Beijing: People’s Music Publishing House.

Tourek, R. (2003). Bach Performance Guide (p. 5). Beijing: People’s Music Publishing House.

Weijieer, G. L. (1986). An Old Pianist's Essay (p. 22). Beijing: Central Conservatory of Music Press.

Westerby, H. (1987). History of Pianoforte Music (pp. 45-46). London: Kegan Paul, Trench, Trubner.

Zhao, X. S. (2000). Piano Playing the Way (p. 163). Beijing: People's Music Publishing House. 